\title{
Overexpression of the RNA-binding proteins Lin28B and IGF2BP3 (IMP3) is associated with chemoresistance and poor disease outcome in ovarian cancer
}

\author{
K-F Hsu ${ }^{1}$, M-R Shen ${ }^{2}$, Y-F Huang ${ }^{1}$, Y-M Cheng ${ }^{1}$, S-H Lin ${ }^{3}$, N-H Chow ${ }^{4}$, S-W Cheng ${ }^{4}$, C-Y Chou ${ }^{\star, 1}$ and C-L Ho ${ }^{*}, 4$ \\ ${ }^{1}$ Department of Obstetrics and Gynecology, National Cheng Kung University Hospital, College of Medicine, National Cheng \\ Kung University, Tainan, Taiwan; ${ }^{2}$ Department of Pharmacology, National Cheng Kung University Hospital, College of Medicine, \\ National Cheng Kung University, Tainan, Taiwan; ${ }^{3}$ Institute of Clinical Medicine, National Cheng Kung University Hospital, College \\ of Medicine, National Cheng Kung University, Tainan, Taiwan and ${ }^{4}$ Department of Pathology, National Cheng Kung University \\ Hospital, College of Medicine, National Cheng Kung University, Tainan, Taiwan
}

Background: RNA-binding proteins have an important role in messenger RNA (mRNA) regulation during tumour development and carcinogenesis. In the present study, we examined the insulin-like growth factor 2 mRNA-binding proteins (IGF2BPs; hereafter refered to as IMPs) and Lin28 family expressions in epithelial ovarian carcinoma (EOC) patients and correlated their expression levels with the response to chemotherapy, hCTR1 expression and patient survival.

Methods: Patients clinical information, real-time RT-PCR, immunohistochemistry, western blot, Transwell migration invasion assays, and cytotoxicity assays were used.

Results: From 140 EOC patients, high expression of IMP3 or Lin28B was associated with poor survival, and women diagnosed at advanced stages with elevated IMP3 and Lin28B were at higher risk of developing chemoresistance. High IMP3 levels combined with high Lin28B levels significantly correlated with the poorest 5-year survival rates. Knockdown of IMP3 or Lin28B decreased cell proliferation, migration, and invasion, and increased the platinum sensitivity, but not taxol sensitivity, of ovarian cancer cells through increased expression of hCTR1, a copper transporter involved in platinum uptake. High expression of hCTR1 correlated with low expression of IMP3/Lin28B and better progression-free survival in advanced-stage EOC patients.

Conclusion: Testing for a combination of elevated IMP3 and Lin28B levels could further facilitate the identification of a patient subgroup with the worst prognosis.

A growing body of evidence indicates that RNA-binding proteins have an important role in mRNA regulation during tumour development and carcinogenesis (Bashirullah et al, 1998; Nielsen et al, 2002; Yaniv and Yisraeli, 2002). The insulin-like growth factor 2 messenger RNA (mRNA)-binding proteins (IGF2BPs), including IMP1 (IGF2BP1), IMP2 (IGF2BP2), and IMP3 (IGF2BP3), belong to an evolutionarily conserved family of
mRNA-binding proteins that regulate mRNA transport, translation, and turnover by binding the coding regions of target mRNAs, such as IGF2, MYC, and ACTB ( $\beta$-actin; Nielsen et al, 2001). IMP3 is a newly identified IGF2BP that is involved in cell growth and migration during the early stages of embryogenesis (Nielsen et al, 1999; Liao et al, 2005; Vikesaa et al, 2006). In addition, IMP3 may act as a novel biomarker that can differentiate 
normal tissues from cancerous tissues (Yantiss et al, 2005; FindeisHosey and $\mathrm{Xu}, 2011)$ and as a prognostic marker in colorectal, hepatocellular, and ovarian clear-cell carcinomas (Jeng et al, 2008; Köbel et al, 2009; Lochhead et al, 2012). However, conflicting results have been reported for epithelial ovarian carcinoma (EOC), in which overexpression of IMP1, but not IMP3, was associated with advanced-stage ovarian cancer, high-histological grade and poor survival ( $\mathrm{Gu}$ et al, 2004).

MicroRNAs (miRNAs) are a new class of small, noncoding RNAs that post-transcriptionally regulate the expression of targetmRNA transcripts involved in proliferation, differentiation, and apoptosis during tumorigenesis (Kumar et al, 2007). The miRNA let-7 was discovered as a critical regulator of stem-cell differentiation in Caenorhabditis elegans (Reinhart et al, 2000) and is thought to be a tumour suppressor because it represses multiple oncogenes (Mayr and Heinemann, 2013). Reduction or loss of let-7 expression is strongly associated with increased tumourigenicity and poor patient prognosis in lung cancer (Esquela-Kerscher and Slack, 2006). Recently, it was reported that the Lin 28 family of RNAbinding proteins blocks let-7 maturation and affects the differentiation and proliferation of embryonic stem cells (Yu et al, 2007). Two Lin28 homologues are found in mammals, Lin28A (Lin28) and Lin28B (Guo et al, 2006). Lin28 is overexpressed in advanced human malignancies and may have an important role in the maintenance of cancer stem cells and the regulation of tumour growth (Peng et al, 2010; Viswanathan and Daley, 2010). In EOC, Lin28/Lin28B overexpression has been observed predominantly in tumours of histological grade 2 or 3 , correlating with advanced disease (Viswanathan and Daley, 2010). Lin28B has been reported to promote IGF2-mediated ovarian cancer progression and serves as an unfavourable prognostic marker for this disease (Lu et al, 2009).

Platinum-based chemotherapy is widely used as the first-line treatment for ovarian cancer. Studies of cisplatin resistance have revealed drug uptake as a critical step that governs cisplatin sensitivity in vitro (Hall et al, 2008). Recently, it was demonstrated that the major copper-influx transporter, copper transporter 1 (CTR1; human CTR1 (hCTR1)), which is involved in the maintenance of copper homeostasis, is also involved in the transport of platinum (Kuo et al, 2007) and has a role in platinum resistance (Ishida et al, 2002, Holzer et al, 2006).

Using a combined bioinformatic and experimental approach on 6118 expressed-sequence tag libraries (Hsu et al, 2011), we have identified IMP1 and Lin28B genes with potential oncofoetalexpression patterns. Because the mechanism underlying the importance of IMPs and the Lin28 family in ovarian cancer has not been well studied, in the present study, we examined IMP and Lin28 expressions in EOC using real-time PCR and correlated their expression levels with the response to chemotherapy, hCTR1 expression, and patient survival.

\section{MATERIALS AND METHODS}

Patients and tissue samples. EOC patients who underwent staging or cytoreductive surgery at the National Cheng Kung University Hospital (NCKUH) in Tainan, Taiwan from January 2002 to January 2008 were consecutively enroled in this study. Clinical and pathological information, including age, stage, cell type, chemo-response, and survival, was collected from medical charts and pathology reports. The staging met the criteria of the International Federation of Gynecology and Obstetrics Classification (FIGO). Histological classification was defined according to the classification standards of the World Health Organization. The medical records and pathological slides of these patients were used to determine clinical characteristics, pathological diagnoses, and outcome information. The overall survival (OS) was calculated from the date of diagnosis. The duration of OS was measured to the date of death from any cause; survivors were censored on the date they were last known to be alive. Progression-free survival (PFS) was measured as the period from surgery to the date of confirmed recurrence or disease progression, or to the date of the investigators' last note of a disease-free status.

The maximal diameter of the residual tumour during surgery was also recorded. Optimal cytoreductive surgery was defined as a maximal residual-tumour diameter $<1 \mathrm{~cm}$, and other cases were defined as suboptimal cytoreductive surgery. Patients received regular follow-ups after completing treatment. Computerized tomography or magnetic resonance imaging was carried out when recurrence was suspected. Recurrences were defined based on abnormal results of imaging studies, aspiration cytology from ascites, elevated tumour markers ( $\geqslant 2$-fold above the upper normal limits) on two consecutive tests at 2-week intervals, or the presence of cancer tissue proven by biopsy. Patients with disease progression or disease recurrence $<6$ months after discontinuing chemotherapy were defined as chemo resistant, whereas those without a recurrence or with recurrence $>6$ months after discontinuing chemotherapy were defined as chemosensitive.

Fresh tumour specimens were collected during surgery, immediately frozen in liquid nitrogen, and stored at $-70^{\circ} \mathrm{C}$ until analysis. Control ovarian epithelia were collected by sharp-scalpel dissection in the operating room from 30 women undergoing hysterectomy for benign uterine diseases. The research protocol and consent form were approved by the NCKUH institutional review board of the hospital, and written informed consent was obtained from each patient. Each frozen sample was histologically analysed by a gynaecological pathologist (C-LH), and only samples containing $>70 \%$ tumour area were included for subsequent RNA extraction.

IMP3, Lin28B knockdown and overexpression and transfection. We used a lentiviral small-hairpin RNA (shRNA) system to knock down IMP3 and Lin28B in the ovarian cancer cell lines. The pLKO.1 plasmids expressing small-hairpin RNAs (shRNAs) were purchased from the National RNAi Core Facility (Academia Sinica, Taipei, Taiwan). The lentivirus particles were obtained from the RNAi Core at the Research Center of Clinical Medicine, (NCKUH, Tainan, Taiwan). To knock down Lin28B or IMP3 expression, three shRNAs for Lin28B and IMP3 were used. The target sequences are listed in Supplementary Table 2. The PLKO_TRC005 plasmid containing a non-hairpin insert was used as a negative control. To determine the expression levels of IMP3 and Lin28B, the ovarian cancer cell lines were screened by western blotting. As shown in Supplementary Figure 1, SKOV3 cells expressed low levels of IMP3, A2780 cells expressed low levels of Lin28B, and BG1 and OVCAR3 cells expressed high levels of both IMP3 and Lin28B. BG-1 and OVCAR3 cells were then infected with shRNA or control lentivirus particles in the presence of $8 \mu \mathrm{g} \mathrm{ml}^{-1}$ polybrene. After $24 \mathrm{~h}$ of infection, the cells were treated with $1 \mu \mathrm{g} \mathrm{ml}^{-1}$ puromycin for selection, and puromycin-resistant cells were pooled for subsequent analysis.

To generate IMP3-overexpressing ovarian cancer cells, the verified full-length cDNA of IMP3 in a C-terminally Myc/DDKtagged pCMV6 vector (Cat. No. RC209597, OriGene Technologies, Rockville, MD, USA) or the corresponding empty vector were transfected into SKOV3 cells using Lipofectamine 2000 (Invitrogen, Carlsbad, CA, USA), according to the manufacturer's protocol. To generate ovarian cancer cell lines overexpressing Lin28B, the Lin28B ORF was amplified from the cDNA of HepG2 cells and then cloned into a pMSCVpuro vector, as described previously (Cheng et al, 2013). After confirming the sequence of the cloned Lin $28 \mathrm{~B}$, the Lin28B plasmid was transfected into A2780 cells. 
Immunohistochemistry and scoring. To analyse IMP3, Lin28B and hCTR1 protein expression in ovarian cancer, immunohistochemistry was performed. After blocking endogenous peroxidase activity, the sections were subjected to heat-induced antigen retrieval using an autoclave. After incubation with mouse monoclonal anti-IMP3 antibody (Clone 69.1, 1:100, Dako, Carpinteria, CA, USA), rabbit polyclonal anti-Lin28B antibody ( $1: 10$, Abcam, Cambridge, UK), hCTR1 primary antibody $(1: 500$, Novus Biologicals, Littleton, CO, USA), binding was detected using a biotin-labelled secondary antibody and the ABC complex method (LSAB kit; Dako). Positive and negative controls were included in all experiments. Two independent pathologists (C-LH and N-HC) analysed the immunohistochemical staining. Each slide was scored semiquantitatively. For IMP3 and Lin $28 \mathrm{~B}$, the staining intensity was scored as follows: 1 , weak staining; 2 , moderate staining; and 3 , strong staining. The staining area was the percentage of positive tumour cells, which was scored as follows: 0, no tumour cell stained; $1,1-10 \%$ positive tumour cells; $2,10-50 \%$ positive tumour cells; or $3,>50 \%$ positive tumour cells. The final immunohistochemical score (IS) for each specimen was obtained by multiplying the staining intensity and area scores, resulting in a value between 0 and 9. Overexpressing tumours with hCTR1 were defined as tumours with diffuse cytoplasmic staining of moderate to strong intensity ( $\geqslant 25 \%$ of cells) and an intensity score $\geqslant 2$ as previously described (Chen et al, 2012).

Statistics. The data represent the mean \pm s.d. For the chemosensitivity assay, the data were analysed using a two-way analysis of variance (ANOVA). Clinical variables except tumour grade were compared using the $\chi^{2}$ test or Student's $t$-test. A one-way ANOVA was used to assess multiple groups with Scheffe's post hoc comparisons. Variables of tumour grade were analysed by Mann-Whitney's $U$-test or Kruskal-Wallis test. Correlations were determined by Pearson or Spearman correlation when appropriate. Survival curves were constructed using the Kaplan-Meier method. The log-rank test was used to determine the significance of the differences in PFS and OS between groups. Univariate and multivariate Cox proportional hazards models used to fit the data to determine the importance of covariates. Factors that were prognostically relevant in the univariate analysis were included in the multivariate Cox analysis. A $P$-value of 0.05 was considered statistically significant. All analyses were performed using the SPSS statistical software package (SPSS Statistics version 16, SPSS, Chicago, IL, USA).

\section{RESULTS}

Clinico-pathological characteristics of the patients and their association with RNA expression levels of IMPs, Lin28 and Lin28B. From January 2002 to January 2008, 229 EOC patients received cytoreductive surgery at NCKUH. Samples demonstrating necrosis, samples with $<70 \%$ tumour cells as determined by $\mathrm{H} \& \mathrm{E}$ staining, or samples with poor RNA quality were excluded from this study. After these exclusions, a total of 140 newly diagnosed EOC patients were recruited into our study. The clinicopathological characteristics of these 140 patients and the mRNA expression levels of IMP1, IMP2, IMP3, Lin28, and Lin28B are displayed in Table 1A. The patients ranged in age from 25 to 81 years (mean, 53.8 years). On the basis of the FIGO classification, 48 patients (34.3\%) were stage I, 10 (7.1\%) were stage II, $69(49.3 \%)$ were stage III, and $13(9.3 \%)$ were stage IV. Of the 140 patients, $123(87.9 \%)$ received adjuvant chemotherapy, which consisted of taxane + platinum or platinum + cyclophosphamide. Seventeen cases (including two cases with advanced-stage disease) did not receive chemotherapy due to early stage disease, rapid aggravation of disease, advanced age, or severe comorbidities. Sixty-seven patients $(47.9 \%)$ had serous tumours and 73 patients had nonserous tumours classified by the following histology: 40 (28.6\%) clear cell, 21 (15.0\%) endometrioid, and 12 (8.6\%) mucinous. Cytoreductive surgery was performed on all patients. Optimal cytoreduction was achieved in 107 patients (76.4\%), and 32 patients $(22.8 \%)$ had suboptimal surgical outcomes. Among the 123 patients who underwent first-line chemotherapy, an overall response occurred in 95 patients (77.2\%). Furthermore, 86 patients (69.9\%) had platinum-sensitive disease. The median follow-up time for all participants was 39 months (range, 1-116 months).

The relationships between the clinico-pathological characteristics and the RNA expression levels of IMPs and the Lin28 family members were evaluated. The expression of IMP1, IMP2, IMP3, Lin28, and Lin28B are shown as the mean \pm s.d. of the ratio between the target-gene expression and PLA expression. As shown in Table 1A, IMP1-, IMP2-, and IMP3 expression levels were significantly upregulated in ovarian cancer compared with normal ovarian tissues and IOSE cells. The expression levels of IMPs or Lin28/Lin28B did not differ significantly between young and old patients, nor did it differ between those who did and those who did not have optimal cytoreductive surgeries. Patients with stage-IV disease were associated with a marginally significant elevated expression of Lin $28 \mathrm{~B}$ compared with stage I-III patients $(P=0.05$, one-way ANOVA). In the cell-type analysis, Lin28 expression was higher in mucinous-type tumours compared with other cell typederived tumours $(P=0.002$, one-way ANOVA). IMP3 levels were higher in clear-cell carcinoma patients than in patients with other cell type-derived tumours, but this difference was not statistically significant. For tumour-grade analysis, as clear-cell type is defined as a high-grade tumour, we subgrouped serous-cell type into highand low-grade tumour; endometrioid type into well-, moderately, and poorly differentiated tumour; mucinous type into well- and poorly differentiated tumour and did analysis. The expression levels of IMPs and Lin28 family between the grade subgroups were not significantly different.

High expression levels of IMP3 and Lin28B were associated with poor prognosis in EOC patients. At the time of their last followup, 64 patients $(45.7 \%)$ were alive without evidence of disease, 11 (7.8\%) were alive with disease, 54 (38.5\%) were dead from disease, and $2(1.4 \%)$ had died from other causes. Among the 140 patients, the median disease-free interval was 24 months (range 0-116 months); 15 patients (10.7\%) had persistent disease and 61 patients (43.5\%) relapsed during follow-up.

The Cox-regression model was used to evaluate the probable clinico-pathological parameters and expression levels of RNAbinding proteins to predict PFS (Table 1B). For each RNA-binding protein gene, a high expression level was defined as a value above the median value, and a low expression level was defined as a value below the median value. Old age, suboptimal cytoreductive surgery, advanced-stage ovarian cancer, and high IMP3 and Lin28B expression levels were significantly associated with a shorter PFS than were young age, optimal cytoreductive surgery, early stage, and low expression levels of IMP3 and Lin28B based on a univariate analysis. The multivariate Cox model showed that optimal cytoreductive surgery, advanced-stage ovarian cancer, and high IMP3 expression were independently associated with poor PFS (Table 1B).

PFS and OS were also estimated and compared between the high and low IMP3 and Lin28B groups (Figure 1). Kaplan-Meier analysis and log-rank tests indicated that patients with either high IMP3 or high Lin28B mRNA levels had significantly shorter OS and PFS rates compared with those with low IMP3 or Lin28B mRNA levels (Figure 1A-D). High IMP3 levels combined with high Lin28B levels significantly correlated with the poorest 5-year PFS $(P<0.001$, Figure $1 \mathrm{E})$ and $\mathrm{OS}(P=0.001$, Figure $1 \mathrm{~F})$. Because IMP3 has been reported to be a prognostic marker in clear-cell 
Table 1A. Clinicopathologic characteristics of patients and association with RNA expression levels of IMPs and Lin28/Lin28B

\begin{tabular}{|c|c|c|c|c|c|c|c|c|c|c|}
\hline & IMP1 & $\begin{array}{c}P- \\
\text { value }\end{array}$ & IMP2 & $\begin{array}{c}P \text { - } \\
\text { value }\end{array}$ & IMP3 & $\begin{array}{c}P- \\
\text { value }\end{array}$ & LIN28B & $\begin{array}{c}P \text { - } \\
\text { value }\end{array}$ & LIN28 & $\begin{array}{c}P \text { - } \\
\text { value }\end{array}$ \\
\hline $\begin{array}{l}\text { Cancer } \\
(n=140)\end{array}$ & $0.07 \pm 0.203$ & $0.03^{a}$ & $0.329 \pm 0.005$ & $0.005^{a}$ & $0.084 \pm 0.01$ & $0.002^{a}$ & $0.029 \pm 0.006$ & & $0.13 \pm 0.02$ & \\
\hline \multicolumn{11}{|c|}{ Normal $(n=30)$} \\
\hline $\begin{array}{l}\text { Tissue } \\
\text { Cell }^{\mathbf{b}}\end{array}$ & $\begin{array}{l}0.003 \pm 0.001 \\
0.009 \pm 0.003\end{array}$ & & $\begin{array}{c}0.047 \pm 0.005 \\
0.02 \pm 0.007\end{array}$ & & $\begin{array}{l}0.004 \pm 0.001 \\
0.004 \pm 0.002\end{array}$ & & $\begin{array}{c}0.04 \pm 0.07 \\
3.11 \pm 2.58\left(\times 10^{-5}\right)\end{array}$ & & $\begin{array}{c}0.15 \pm 0.10 \\
3.68 \pm 1.67\left(\times 10^{-4}\right)\end{array}$ & \\
\hline \multicolumn{11}{|l|}{ Age } \\
\hline $\begin{array}{l}<50 \text { years } \\
\geqslant 50 \text { years }\end{array}$ & $\begin{array}{l}0.032 \pm 0.08 \\
0.092 \pm 0.24\end{array}$ & 0.09 & $\begin{array}{l}0.31 \pm 0.62 \\
0.32 \pm 0.45\end{array}$ & 0.89 & $\begin{array}{l}0.080 \pm 0.12 \\
0.083 \pm 0.14\end{array}$ & 0.88 & $\begin{array}{l}0.014 \pm 0.077 \\
0.037 \pm 0.009\end{array}$ & 0.1 & $\begin{array}{l}0.145 \pm 0.250 \\
0.115 \pm 0.221\end{array}$ & 0.5 \\
\hline \multicolumn{11}{|l|}{ Stage } \\
\hline $\begin{array}{l}\text { I } 48(34.3 \%) \\
\text { II } 10(7.1 \%) \\
\text { III } 69(49.3 \%) \\
\text { IV } 13(9.3 \%)\end{array}$ & $\begin{array}{l}0.695 \pm 0.642 \\
0.012 \pm 0.01 \\
0.138 \pm 0.065 \\
0.135 \pm 0.039\end{array}$ & 0.69 & $\begin{array}{l}0.260 \pm 0.047 \\
0.128 \pm 0.05 \\
0.393 \pm 0.079 \\
0.399 \pm 0.190\end{array}$ & 0.38 & $\begin{array}{l}0.094 \pm 0.023 \\
0.018 \pm 0.012 \\
0.070 \pm 0.013 \\
0.169 \pm 0.058\end{array}$ & 0.06 & $\begin{array}{c}0.033 \pm 0.01 \\
0.006 \pm 0.003 \\
0.021 \pm 0.006 \\
0.07 \pm 0.02\end{array}$ & 0.05 & $\begin{array}{l}0.112 \pm 0.027 \\
0.231 \pm 0.123 \\
0.125 \pm 0.028 \\
0.146 \pm 0.08\end{array}$ & 0.57 \\
\hline \multicolumn{11}{|l|}{ Cell type } \\
\hline $\begin{array}{l}\text { Serous } \\
67(47.9 \%) \\
\text { Clear cell } \\
40 \text { (28.6\%) } \\
\text { Endometrioid } \\
21(15 \%) \\
\text { Mucinous } \\
12(8.6 \%)\end{array}$ & $\begin{array}{l}0.065 \pm 0.027 \\
0.077 \pm 0.030 \\
0.036 \pm 0.011 \\
0.146 \pm 0.08\end{array}$ & 0.48 & $\begin{array}{l}0.364 \pm 0.074 \\
0.240 \pm 0.075 \\
0.348 \pm 0.114 \\
0.404 \pm 0.129\end{array}$ & 0.669 & $\begin{array}{l}0.071 \pm 0.015 \\
0.121 \pm 0.027 \\
0.057 \pm 0.019 \\
0.074 \pm 0.043\end{array}$ & 0.24 & $\begin{array}{l}0.031 \pm 0.007 \\
0.014 \pm 0.006 \\
0.067 \pm 0.037 \\
0.002 \pm 0.001\end{array}$ & 0.07 & $\begin{array}{l}0.078 \pm 0.021 \\
0.101 \pm 0.031 \\
0.129 \pm 0.048 \\
0.493 \pm 0.105\end{array}$ & 0.002 \\
\hline \multicolumn{11}{|c|}{ Tumour grade } \\
\hline $\begin{array}{l}\text { Serous } \\
\text { High grade } \\
64 \\
\text { Low grade } \\
3\end{array}$ & $\begin{array}{l}0.064 \pm 0.218 \\
0.005 \pm 0.008\end{array}$ & 0.10 & $\begin{array}{l}0.358 \pm 0.588 \\
0.136 \pm 0.101\end{array}$ & 0.94 & $\begin{array}{l}0.070 \pm 0.121 \\
0.029 \pm 0.042\end{array}$ & 0.80 & $\begin{array}{l}0.032 \pm 0.057 \\
0.009 \pm 0.015\end{array}$ & 0.48 & $\begin{array}{l}0.074 \pm 0.171 \\
0.107 \pm 0.097\end{array}$ & 0.08 \\
\hline \multicolumn{11}{|l|}{ Endometrioid } \\
\hline $\begin{array}{l}\text { Well } \\
\text { differentiated } \\
6 \\
\text { Moderately } \\
\text { differentiated } \\
7 \\
\text { Poorly } \\
\text { differentiated } \\
8\end{array}$ & $\begin{array}{l}0.070 \pm 0.062 \\
0.035 \pm 0.063 \\
0.016 \pm 0.027\end{array}$ & & $\begin{array}{l}0.775 \pm 0.878 \\
0.201 \pm 0.226 \\
0.221 \pm 0.25\end{array}$ & & $\begin{array}{l}0.046 \pm 0.053 \\
0.022 \pm 0.036 \\
0.094 \pm 0.123\end{array}$ & & $\begin{array}{l}0.059 \pm 0.096 \\
0.104 \pm 0.260 \\
0.040 \pm 0.098\end{array}$ & & $\begin{array}{l}0.175 \pm 0.285 \\
0.071 \pm 0.072 \\
0.152 \pm 0.262\end{array}$ & \\
\hline \multicolumn{11}{|l|}{ Mucinous } \\
\hline $\begin{array}{c}\text { Well } \\
9 \\
\text { Poor } \\
3\end{array}$ & $\begin{array}{l}0.170 \pm 0.350 \\
0.002 \pm 0.003\end{array}$ & & $\begin{array}{c}0.581 \pm 0.45 \\
0.042 \pm 0.032\end{array}$ & & $\begin{array}{l}0.109 \pm 0.175 \\
0.006 \pm 0.005\end{array}$ & & $\begin{array}{l}0.003 \pm 0.007 \\
0.001 \pm 0.001\end{array}$ & & $\begin{array}{l}0.369 \pm 0.365 \\
0.714 \pm 0.287\end{array}$ & \\
\hline \multicolumn{11}{|c|}{ Residual tumour (cm) } \\
\hline $\begin{array}{rl}<1 & 107(76.4 \%) \\
\geqslant & 1 \\
& 32(22.8 \%)\end{array}$ & $\begin{array}{l}0.067 \pm 0.01 \\
0.079 \pm 0.02\end{array}$ & 0.81 & $\begin{array}{l}0.349 \pm 0.055 \\
0.243 \pm 0.087\end{array}$ & 0.38 & $\begin{array}{l}0.075 \pm 0.012 \\
0.122 \pm 0.035\end{array}$ & 0.11 & $\begin{array}{l}0.031 \pm 0.008 \\
0.027 \pm 0.009\end{array}$ & 0.98 & $\begin{array}{l}0.134 \pm 0.023 \\
0.123 \pm 0.054\end{array}$ & 0.85 \\
\hline $\begin{array}{l}\text { Abbreviation: IMP } \\
{ }^{a} \text { Cancer tissue co } \\
{ }^{b} \text { Data shown as } m\end{array}$ & $\begin{array}{l}\text { din-like growth fa } \\
\text { d with normal tis } \\
\text { alue of IOSE-398 }\end{array}$ & $2 \mathrm{mRI}$ & $\begin{array}{l}\text { binding proteins } \\
5 \text { cells. }\end{array}$ & $\mathrm{FF} 2 \mathrm{BPs}$ & ered to as (MPs). & & & & & \\
\hline
\end{tabular}

ovarian cancer (Köbel et al, 2009), we further compared PFS in clear-cell carcinoma $(n=40)$ with that in other subtypes $(n=100)$. As shown in Supplementary Figure 2, the PFS rate of clear-cell carcinoma patients with high IMP3 levels was shorter than that in clear-cell carcinoma patients with low IMP3 levels, but the difference was not statistically significant $(P=0.13$, log-rank test). In contrast, the PFS rate in high IMP3-expressing non-clear-cell ovarian carcinoma was significantly lower compared with that of non-clear-cell ovarian carcinoma cases with low IMP3 levels
$(P=0.01$, log-rank test; Supplementary Figure $2 \mathrm{~B})$. Intriguingly, patients with high Lin28B expression had significantly shorter PFS than those with low Lin28B regardless of cell type $(P=0.02$ for clear-cell cancer; $P=0.01$ for non-clear-cell types, log-rank test; Supplementary Figure 2C and D). To validate the existence of a correlation between RNA and protein expression levels of IMP3 and Lin28 in ovarian cancer tissues, all 140 paraffin-embedded ovarian carcinoma tissues were examined by immunohistochemistry. The results showed IMP3 and Lin28B expression by mRNA 
Table 1B. Univariate and multivariate Cox proportional hazards regression model for progression-free survival $(n=140)$

\begin{tabular}{|l|c|c|c|c|}
\hline Variables & Univariate $P$-value & HR (95\% Cl) & Multivariate $P$-value & HR (95\% Cl) \\
\hline Age & 0.013 & $1.023(1.005-1.042)$ & 0.875 & $2.10(1.25-3.52)$ \\
\hline $\begin{array}{l}\text { Optimal cytoreductive } \\
\text { surgery }\end{array}$ & $<0.001$ & $3.55(2.15-5.86)$ & 0.005 & $7.17(3.79-13.58)$ \\
\hline Stage III/IV vs I/II & $<0.001$ & $8.11(4.33-15.19)$ & $<0.001$ & \\
\hline IMP1 & 0.92 & $0.97(0.63-1.51)$ & & $1.57(1.01-2.48)$ \\
\hline IMP2 & 0.61 & $1.11(0.72-1.74)$ & & 0.05 \\
\hline IMP3 & 0.015 & $1.73(1.10-2.71)$ & 0.08 & \\
\hline Lin28B & 0.007 & $1.84(1.18-2.86)$ & & \\
\hline Lin28 & 0.23 & $0.76(0.48-1.18)$ & & \\
\hline Abbreviation: $\mathrm{Cl}=$ confidence interval; $\mathrm{HR}=$ hazard ratio; IMP=insulin-like growth factor 2 mRNA-binding proteins (IGF2BPs; refered to as IMPs). &
\end{tabular}

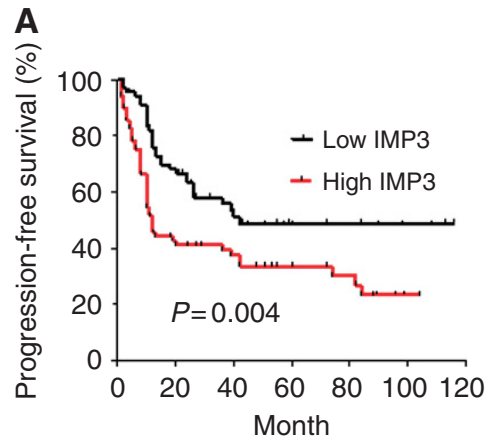

C

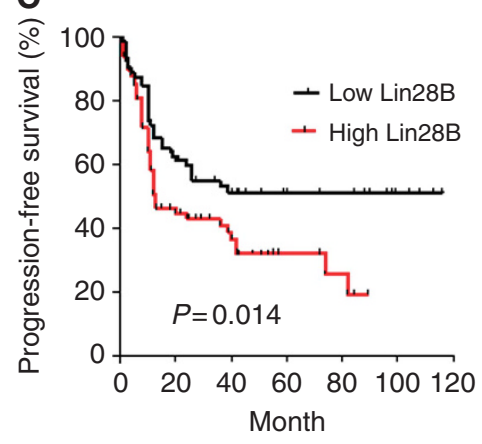

E

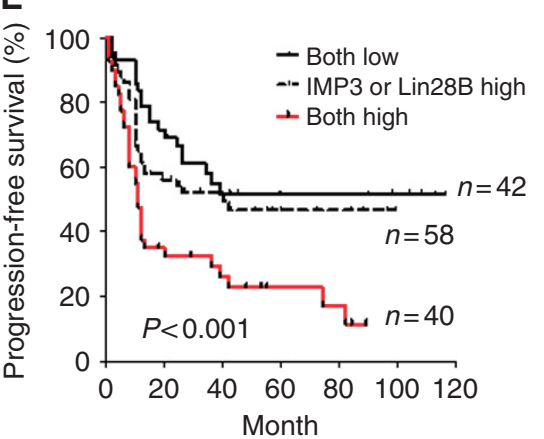

B

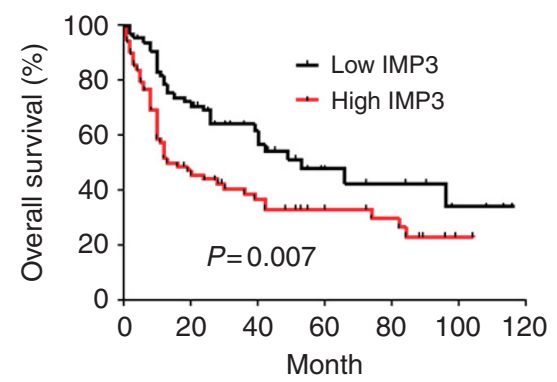

D

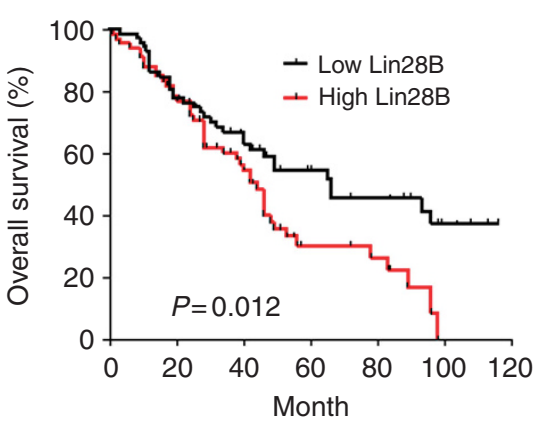

$\mathbf{F}$

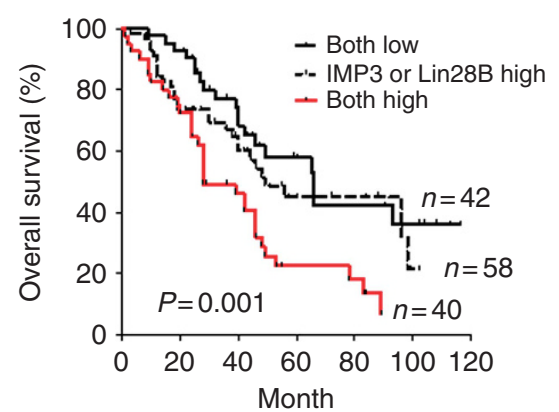

Figure 1. EOC patients with high IMP3 and Lin28B expression have poor prognosis. Kaplan-Meier PFS of 140 EOC patients in relation to the levels of IMP3 (A), Lin28B (C), and both IMP 3 and Lin28B (E). OS in relation to the levels of IMP3 (B), Lin28B (D), and both IMP3 and Lin28B (F).

levels correlated strongly to the status of protein expression (Supplementary Figure 3, (i) IMP3, $r=0.81, P<0.001$; (ii) Lin28B, $r=0.080, P<0.001$, Spearman's correlation).

Knockdown of IMP3 and Lin28B decreased cell proliferation, migration and invasion in BG-1 and OVCAR3 ovarian cancer cells. Because the prognostic association with IMP3 and Lin28B expression may be related to biological effects on invasion and metastasis, we examined the proliferation, migration and invasion of BG-1 and OVCAR3 ovarian cancer cells in vitro. BG-1 (Figure 2) or OVCAR3 (Supplementary Figure 4) cells expressing either control vector (shControl), two different Lin28B-specific shRNAs (shLin28B-508 and shLin28B-860), or two different IMP3-specific shRNAs (shIMP3-596 and shIMP3-268) were derived and selected using lentivirus infection. Knockdown of Lin28B or IMP3 expression was confirmed by western blot analysis 

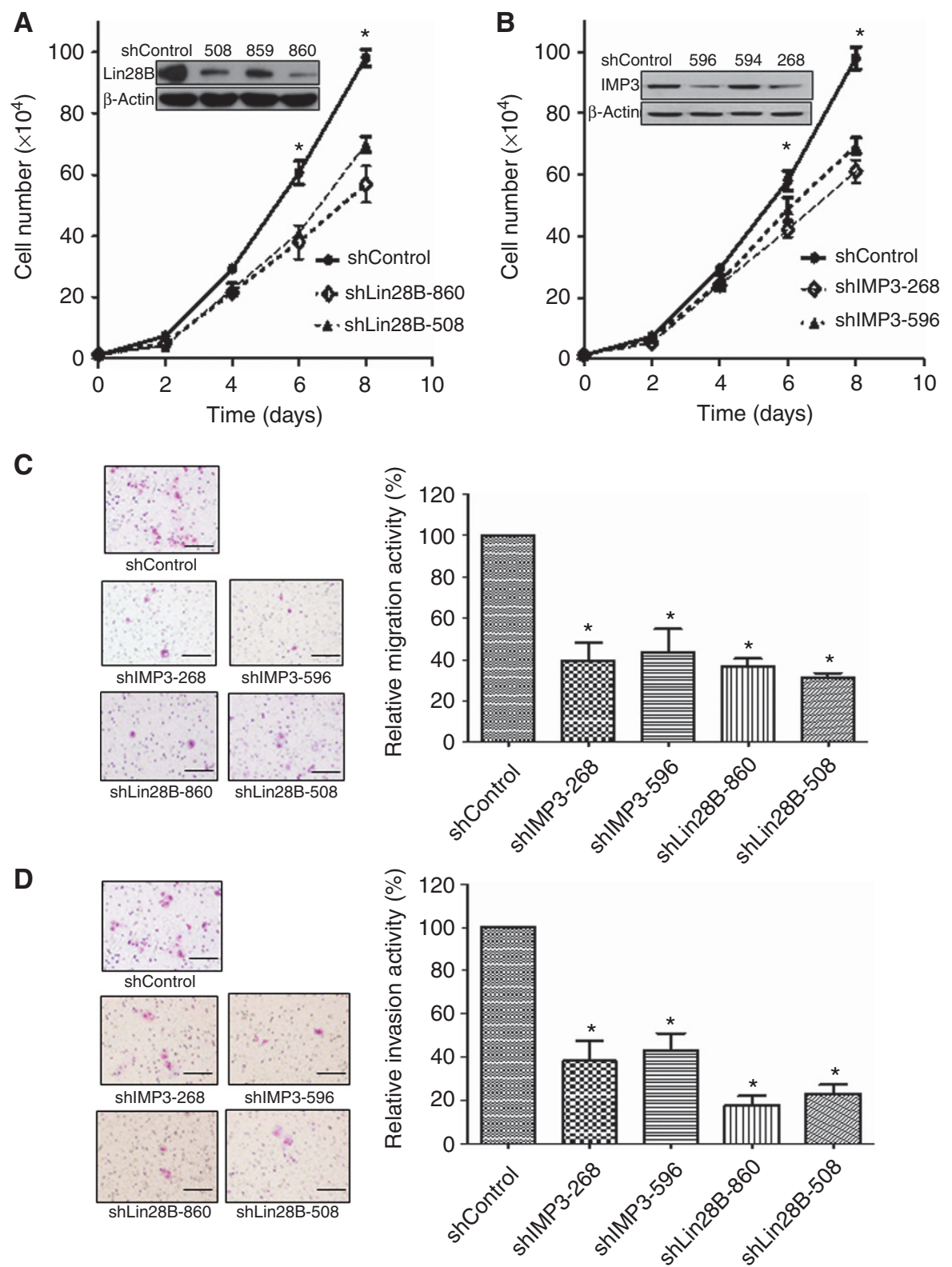

Figure 2. IMP3 and Lin28B knockdown resulted in reduction of proliferation, migration, and invasion in ovarian cancer BG-1 cells. (A, B) Cell proliferation of shControl cells (shControl), Lin28B-knockdown cells (shLin28B-860, shLin28B-508) and shIMP3-knockdown cells (shIMP3-268, shIMP3-596). Knockdown of Lin28B or IMP3 was confirmed by western blot analysis (inserts). Each point on the curve represents the mean cell number \pm s.e.m. $(n=3)$. ${ }^{*} P<0.05$, compared with shControl. Comparisons of the migration $(\mathbf{C})$ and invasion $(\mathbf{D})$ activities between the shControl BG-1 cells (shControl), Lin28B-knockdown BG-1 cells (shLin28B-860, shLin28B-508) and shIMP3-knockdown BG-1 cells (shIMP3-268, shIMP3-596) determined by in vitro Transwell invasion and migration assays. Relative migration and invasion activities in Lin28B- or IMP3-knockdown cells were calculated in relation to the number of cells in the shControl group. Each group was plated in triplicate in each experiment, and each experiment was repeated at least three times. ${ }^{*} P<0.05$, compared with controls. Bar $=100 \mu \mathrm{m}$.

(Figures 2A and B, Supplementary Figure 4A and B, insets). Cell growth significantly decreased after the knockdown of Lin28B or IMP3 by $30 \%$ and $40 \%$, respectively, in BG-1 cells and $41 \%$ and $33 \%$, respectively, in OVCAR3 cells compared with shControl cells over an 8-day interval (Figure 2A and B, Supplementary Figure 4A and B). In addition, the knockdown of Lin28B or IMP3 reduced migration by $39.2 \%$ (shIMP3-268), 43.6\% (shIMP3-596), $36.7 \%$ (shLin28B-860), and 31.3\% (shLin28B-508) compared with shControl BG-1 cells (Figure 2C) and 36.6\% (shIMP3-268), $45.6 \%$ (shIMP3-596), 48\% (shLin28B-860), and 33.6\% (shLin28B-508) compared with shControl OVCAR3 cells (Supplementary Figure 4C). Similarly, knockdown in BG-1 cells reduced invasion by $38.1 \%$ (shIMP3-268), 43.2\% (shIMP3-596), 17.6\% (shLin28B-
860 ), and $23.1 \%$ (shLin28B-508) compared with shControl cells (Figure 2D) and 21.4\% (shIMP3-268), 38.6\% (shIMP3-596), 24.3\% (shLin28B-860), and 38\% (shLin28B-508) in OVCAR3 cells (Supplementary Figure 4D). Our results showing the effect of IMP3 silencing on cell adhesion and migration are consistent with the findings from previous report (Vikesaa et al, 2006).

IMP3 and Lin28B expression levels correlate with chemoresponse in advanced-stage ovarian cancer and cell lines. Because chemosensitivity is an important prognostic factor in ovarian cancer, especially in advanced ovarian cancer, we further evaluated the relationship between chemosensitivity and the expression of IMPs, Lin28, and Lin28B in 80 advanced-staged EOC patients undergoing 
Table 2. The relationship between chemosensitivity and the RNA expression levels of IMPs and Lin28/Lin28B ( $n=80$ )

\begin{tabular}{|c|c|c|c|c|c|c|c|c|c|c|c|c|c|c|c|}
\hline & IMP1 & & & IMP2 & & & IMP3 & & & Lin28B & & & Lin28 & & \\
\hline & L & $\mathrm{H}$ & & L & $\mathrm{H}$ & & L & $\mathrm{H}$ & & L & $\mathrm{H}$ & & L & $\mathrm{H}$ & \\
\hline Resistant & 20 & 20 & $P=0.90$ & 19 & 21 & $P=0.50$ & 13 & 27 & $P=0.003$ & 15 & 25 & $P=0.04$ & 22 & 17 & $P=0.18$ \\
\hline Sensitive & 21 & 19 & & 17 & 23 & & 26 & 14 & & 24 & 16 & & 17 & 24 & \\
\hline
\end{tabular}

Abbreviations: $\mathrm{H}=$ high expression, mRNA expression value over than median value; IMP = insulin-like growth factor 2 mRNA-binding proteins (IGF2BPs; refered to as IMPs); $\mathrm{L}=$ low expression, mRNA expression value less than median value. Sensitive was defined as a recurrence after a platinum-free interval $\geqslant 6$ months. Resistant was defined as a recurrence after a platinum-free interval of $<6$ months.
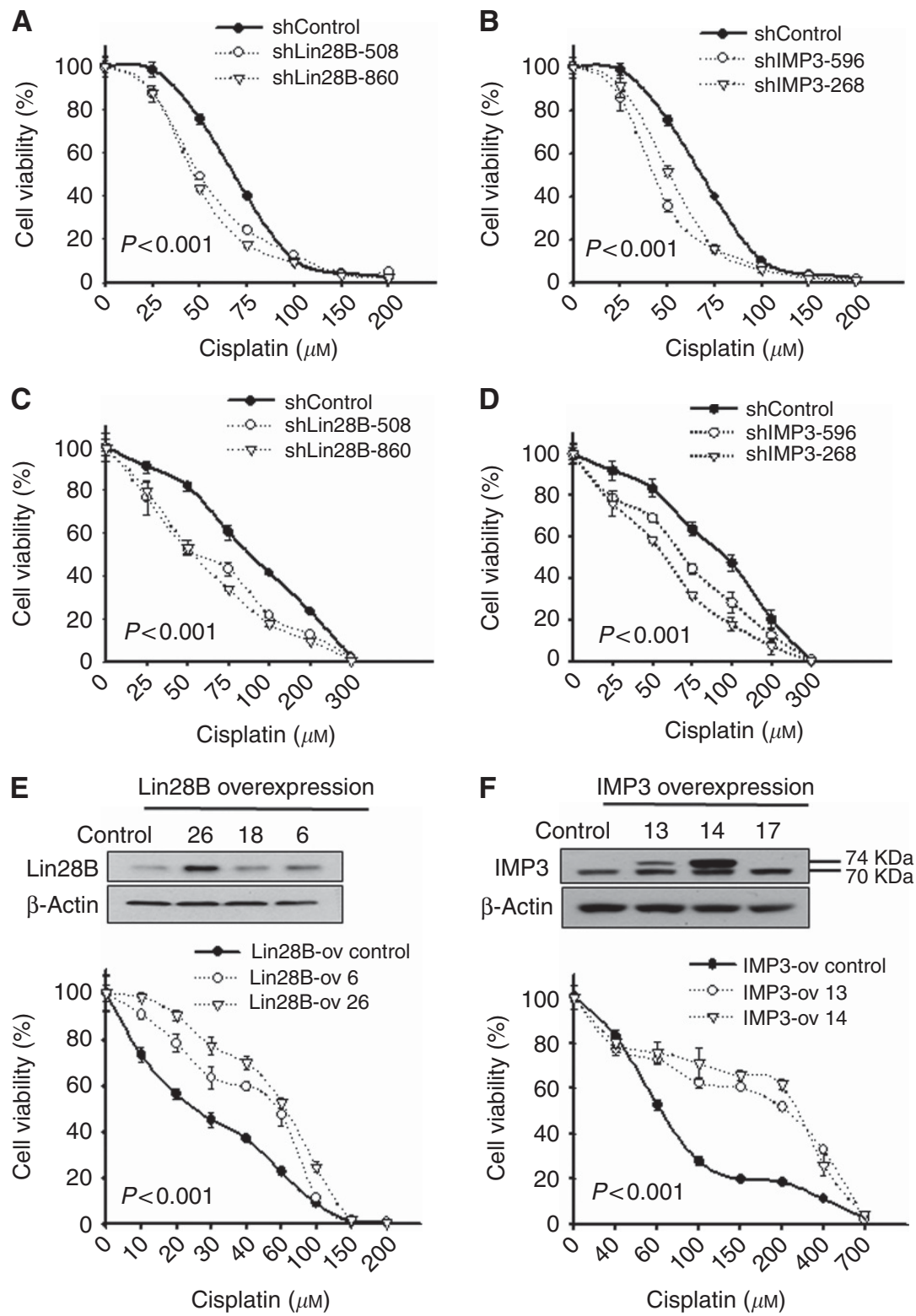

Figure 3. Lin28B and IMP3 expression levels correlate with the sensitivity to cisplatin in ovarian cancer cell lines. BG-1 cells (A, B) and OVCAR3 cells (C, D) expressing a control vector (shControl), two different Lin28B-specific shRNAs (shLin28B-508 and shLin28B-860) or IMP3-specific shRNAs (shIMP3-596 and shIMP3-268) were subjected to the cytotoxicity assay following $24 \mathrm{~h}$ of cisplatin treatment at different concentrations. Cells with Lin28B or IMP3 knockdown displayed increased sensitivity to cisplatin treatment. A2780 (E) and SKOV3 cells (F) stably transfected with Lin28B (Lin28B-ov 6, Lin28B-ov 26), IMP3 (IMP3-ov 13, IMP3-ov 14), or control vector (Lin28-ov control, IMP3-ov control) were subjected to cytotoxicity assays following $24 \mathrm{~h}$ of cisplatin treatments at different concentrations. Overexpression of Lin28B or IMP3 was confirmed by western blot analysis (E, F upper panel). Cells overexpressing Lin28B or IMP3 displayed decreased sensitivity to cisplatin treatment. All $P$-values are $<0.001$.

adjuvant chemotherapy. A median value cut-off was used to categorise the tumours into groups of high or low expression (i.e., the thresholds between high and low expression were as follows: IMP1, 0.005; IMP2, 0.139; IMP3, 0.011; Lin28, 0.014; and Lin28B, $0.004)$. As shown in Table 2 , advanced ovarian cancer patients with high IMP3 or Lin28B mRNA levels had a significantly higher chance of developing chemo-resistant disease.

To further investigate the mechanisms underlying the effects of IMP3 and Lin28B on platinum sensitivity in vitro, Lin28B- and IMP3-knockdown BG-1 (Figure 3A and B), and OVCAR3 
(Figure 3C and D) cells and cells overexpressing Lin28B (A2780 cells, Figure 3E) or IMP3 (SKOV3 cells, Figure 3F) were subjected to cytotoxicity assays after $24 \mathrm{~h}$ of cisplatin or Taxol treatment at various concentrations. In Lin28B-knockdown BG-1 cells, the cisplatin $\mathrm{IC}_{50}$ values were $49.09 \mu \mathrm{M}$ (shLin28B-508) and $45.6 \mu \mathrm{M}$ (shLin28B-860), whereas the $\mathrm{IC}_{50}$ was $66.2 \mu \mathrm{M}$ in the shControl cells (Figure $3 \mathrm{~A}$ ). In Lin28B-knockdown OVCAR3 cells, the $\mathrm{IC}_{50}$ values were $59.1 \mu \mathrm{M}$ (shLin28B-508) and $59.8 \mu \mathrm{M}$ (shLin28B-860) compared with $112.7 \mu \mathrm{M}$ in shControl cells (Figure 3C). Similarly, BG-1 shIMP3-596 and shIMP3-268 cells exhibited IC $_{50}$ values of $41.67 \mu \mathrm{m}$ and $50.66 \mu \mathrm{m}$, respectively (Figure $3 \mathrm{~B}$ ), whereas OVCAR3 shIMP3-596 and shIMP3-268 cells exhibited IC $_{50}$ values of $75.2 \mu \mathrm{M}$ and $59.7 \mu \mathrm{M}$, respectively (Figure 3D). These data indicate that the knockdown of Lin28B or IMP3 significantly increased sensitivity to cisplatin in ovarian cancer cells $(P<0.001$, two-way ANOVA). In contrast, sensitivity to Taxol was unaffected by Lin28B or IMP3 knockdown (Supplementary Figure 5). For further evidence, the effect of overexpressing Lin28B and IMP3 on platinum sensitivity was also assessed in other ovarian cancer cell lines. A2780 cells (Figure 3E) and SKOV3 cells (Figure 3F) were stably transfected with Lin28B (Lin28B-ov 6, Lin28B-ov 26), IMP3 (IMP3-ov13, IMP3-ov14), or the appropriate control vectors. The overexpression of Lin28B or IMP3 was confirmed by western blot analysis (Figure $3 \mathrm{E}$ and F). Notably, there was a double band visible for IMP3 in the IMP3-overexpressing clones (Figure 3F). The upper band represents exogenous IMP3 with a molecular weight of $\sim 73.7 \mathrm{kDa}$, which is slightly larger than the endogenous IMP3 (70.0 kDa, lower band) due to the addition of a Myc/DDK tag. Lin28B-ov 6 and Lin28B-ov 26 cells exhibited $\mathrm{IC}_{50}$ values of $54.94 \mu \mathrm{M}$ and $63.32 \mu \mathrm{M}$, respectively, whereas Lin28B-ov Control cells had an $\mathrm{IC}_{50}$ of $25.35 \mu \mathrm{M}$. Similarly, IMP3-ov13 and IMP3ov14 cells exhibited IC $_{50}$ values of $203.92 \mu \mathrm{M}$ and $253.25 \mu \mathrm{M}$, respectively, which were significantly higher than the $\mathrm{IC}_{50}$ of $61.58 \mu \mathrm{M}$ in the control cells. These results indicate that overexpression of Lin28B and IMP3 attenuated ovarian cancer cell sensitivity to cisplatin treatment. No differences in the sensitivity to Taxol treatment were observed between the Lin28- or IMP3overexpressing cells and control cells (data not shown).

The effect of IMP3 and Lin28B on platinum sensitivity is mediated by hCTR1. The hCTR1 has been reported to mediate the uptake of cisplatin in cultured cells (Kuo et al, 2007) and is associated with responsiveness to platinum-based therapy in human ovarian tumours (Ishida et al, 2010). Therefore, we studied the relationship between hCTR1 and IMP3/Lin28B. Knockdown of Lin28B or IMP3 in BG-1 cells increased hCTR1 protein expression by 2.5 - to 3.06-fold compared with control cells (Figure 4A). Copper histidine is a chelated formulation of copper used clinically to treat copper metabolism disorders (Sarkar et al, 1993). Copper histidine is a substrate of hCTR1 and also inhibits the hCTR1-mediated cellular uptake of platinum in vitro (Ip et al, 2013). Cells were treated with different concentrations of cisplatin $(0-200 \mu \mathrm{M})$ for $24 \mathrm{~h}$ in the presence or absence of copper histidine $\left(3 \times 10^{3} \mu \mathrm{M}\right)$. The $\mathrm{IC}_{50}$ of cisplatin in shLin28B-860, shLin28B-508, shIMP3-268, and shIMP3596 BG-1 cells increased in the presence of copper histidine $(P<0.05$, student's $t$-test $)$ compared with those without the addition of copper histidine. Copper histidine treatment did not significantly affect the $\mathrm{IC}_{50}$ of cisplatin in shControl BG-1 cells (Figure 4B). These results indicate that blocking hCTR1 function may restore cell resistance to cisplatin following IMP3/Lin28B knockdown.

Because both IMP3 and Lin28B had a similar effect on hCTR1, we analysed the possible interaction between these two proteins. However, knockdown or overexpression of Lin28B did not interfere with the expression of IMP3 (Figure 4C, upper panel); likewise, knockdown or overexpression of IMP3 did not affect Lin28B expression (Figure 4C, lower panel). Furthermore, the correlation between IMP3 and Lin28B expression levels in the 140 tumour samples analysed was very low $(\boldsymbol{r}=0.0001, P>0.05$, Pearson's correlation; Figure 4D). Altogether, our results suggest that IMP3 and Lin28B might regulate hCTR1 through different mechanisms.

HCTR1 expression was negatively associated with IMP3 and Lin28B in ovarian cancer tissues, and high hCTR1 expression was associated with a better prognosis. To investigate the clinical significance of hCTR1 and the relationship between hCTR1 and IMP3/Lin28B expression in ovarian cancer tissues, 80 tumours from advanced-stage EOC were immunostained for IMP3, Lin28B, and hCTR1 expression. IMP3 and Lin28B protein expression were defined as high level when IS $\geqslant 2$, and hCTR1 was scored as previously described (Chen et al, 2012). Most tumours with high hCTR1 expression also expressed low levels of IMP3 and Lin28B $(P=0.005$ and 0.001 , respectively; Figure 4E). Furthermore, patients with high hCTR1 expression had a longer PFS than those with low-hCTR1 expression ( $P=0.0035$, log-rank test; Figure $4 \mathrm{~F})$.

\section{DISCUSSION}

In this study, we identified IMP3 and Lin28B as candidate biomarkers of resistance to platinum-based chemotherapy and poor clinical outcome in EOC patients. Moreover, tumours overexpressing IMP3/Lin28B displayed reduced-hCTR1 expression, which induces chemoresistance to platinum and may account for the increased tumour recurrence and shorter PFS observed in EOC patients.

IMPs are frequently overexpressed in various cancers, and they are considered to be oncofoetal factors ( $\mathrm{Gu}$ et al, 2004; Hsu et al, 2011). IMP3 expression is low or undetectable in non-neoplastic adult tissue (Nielsen et al, 1999). However, in tumour cells, IMP3 promotes tumour cell proliferation by inducing the expression of several oncogenes (i.e., IGF2 and MYC) through mRNA stabilization (Liao et al, 2005) and exerts profound effects on cellular adhesion and invasion by stabilizising CD44 mRNA (Vikesaa et al, 2006). Recent studies have demonstrated that IMP3-positive renal cells, as well as colorectal and endometrial carcinomas, exhibit increased metastatic potential (Jiang et al, 2006; Zheng et al, 2008; Yuan et al, 2009), and IMP3 was is a negative prognostic factor in hepatocellular (Jeng et al, 2008) and clear-cell ovarian cancers (Köbel et al, 2009). In contrast, a different study reported that IMP1 but not IMP3 overexpression, is a prognostic marker for patients with clear-cell ovarian cancer ( $\mathrm{Gu}$ et al, 2004). Our findings differ from those reported by Köbel et al (2009). First, in the present study, the PFS rate of clear-cell carcinoma patients with high IMP3 levels was not significantly different from those with low IMP3 levels, whereas the PFS rate in high IMP3-expressing non-clear-cell ovarian carcinoma was significantly lower compared with that with low IMP3 levels. In contrast, Köbel et al (2009) showed a significant correlation between IMP3 protein expression and survival in patients with clear-cell ovarian cancer, but not in high-grade serous or endometrioid ovarian cancer subtypes. Second, the strength of the study by Köbel et al (2009) is the large-sample size further reinforced by validation in an independent case series. One limitation of our study is the sample size for each of the subtypes of EOC examined. Further investigation in a large-sample cohort is warranted to determine not only IMP3 and Lin28B expression in different EOC subtypes but also their usefulness in monitoring the treatment responses.

Lin28/Lin28B is expressed in early embryogenesis (Polesskaya et al, 2007) and normal gonadal cells (Xue et al, 2011; Grieco et al, 2013) but exhibits little to no expression in normal ovarian cells, as shown by the expression levels of IOSE cells in Table 1A. The observation of relatively high levels of Lin28/Lin28B expression in normal ovarian epithelial tissues was most likely due to 
A
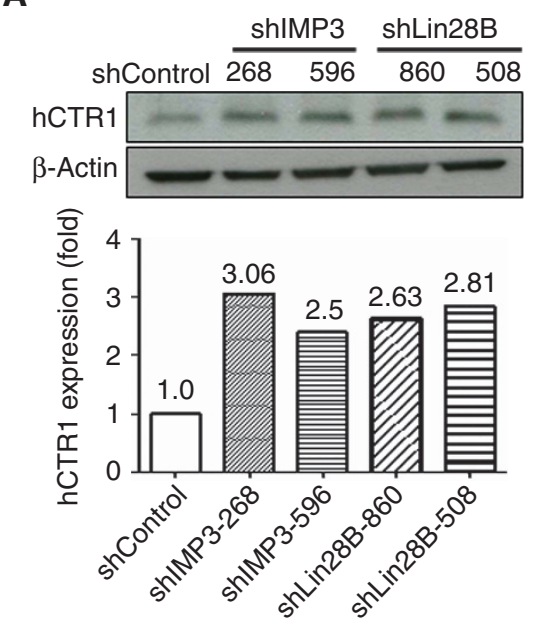

C
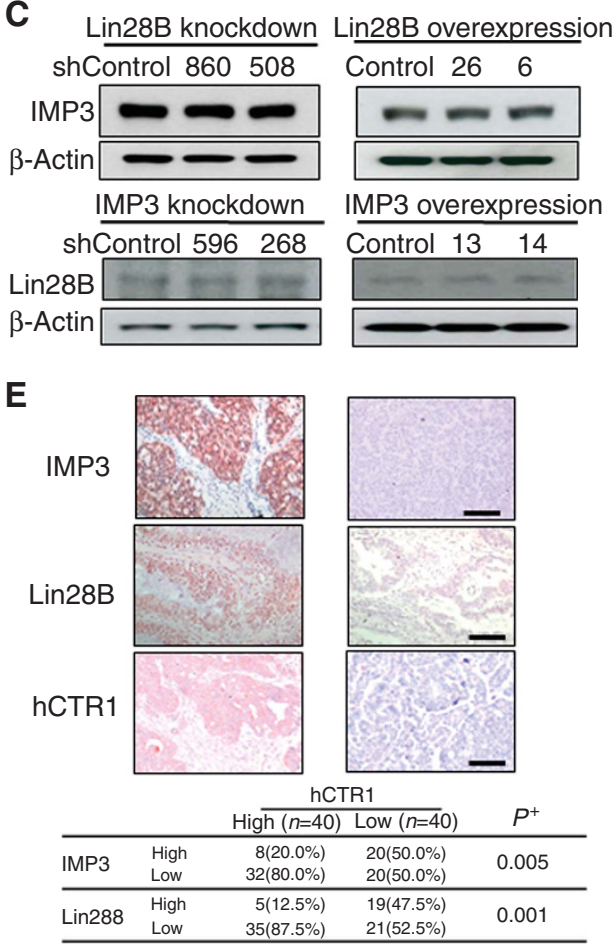

B

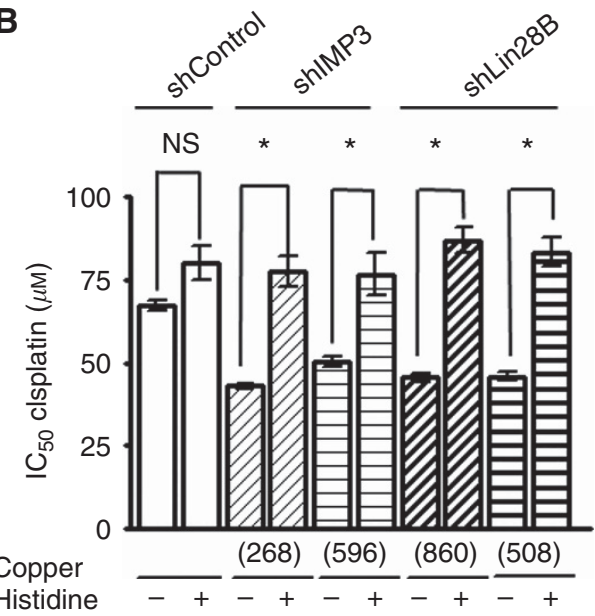

D

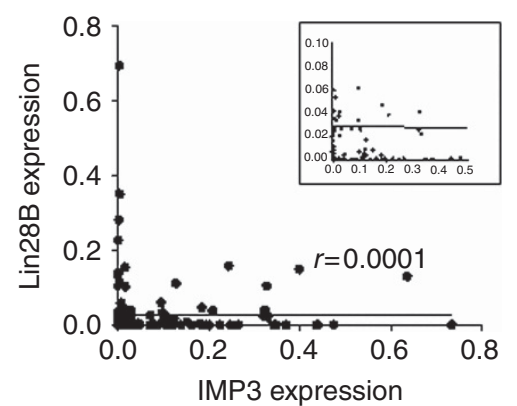

$\mathbf{F}$

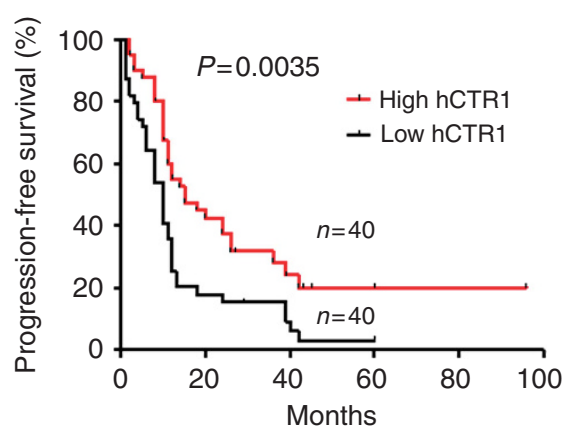

Figure 4. IMP3/Lin28B knockdown upregulated hCTR1 expressions in ovarian cancer cells, and patients with high hCTR1 expression in tumors were associated with better prognosis. (A) hCTR1 expression in shControl cells (shControl), Lin28B-knockdown cells (shLin28B-860, shLin28B-508) and IMP3-knockdown cells (shIMP3-268, shIMP3-596) were determined by immuno-blotting with an hCTR1 antibody. Lin28B- or IMP3-knockdown cells showed increased expression of hCTR1. hCTR1 and $\beta$-actin levels were quantitated by densitometry and ratios were determined. (B) Cells were treated with different concentrations $(0-200 \mu \mathrm{m})$ of cisplatin for $24 \mathrm{~h}$ in the presence or absence of copper histidine $\left(3 \times 10^{3} \mu \mathrm{M}\right)$. The $\mathrm{IC}_{50}$ values increased in IMP3- or Lin28B-knockdown cells when combined with copper histidine $\left({ }^{*} P<0.05\right)$ whereas no significant (NS) effect was observed in shControl cells. (C) Cells with Lin28B knockdown or overexpression were immune-blotted with IMP3 antibody (upper panel) or Lin28B antibody (lower panel). (D) Correlation between IMP3 and Lin28B expression in 140 EOC samples. A large number of tumour samples with very low-RNA expression of IMP3, Lin28B were shown in Insert. (E) Relationship between hCTR1 expression and levels of IMP3 and Lin28B in tumor specimens from 80 advanced-stage EOC patients by IHC analysis. Upper panel, immunohistochemical stains for IMP3, Lin28B and hCTR1 in representative EOC samples. Upper left panel, carcinoma cells showed IMP3, Lin28B, and hCTR1 overexpression manifested by diffuse cytoplasmic/nuclear staining of strong intensity $(200 \times)$. Upper right panel, carcinoma cells showed low immunostaining activity of IMP3, Lin28B and hCTR1 $(200 \times)$. Bar $=100 \mu \mathrm{m}(\mathrm{F})$ The PFS of 80 advanced-stage EOC patients with high- and low-expressing hCTR1 levels.

contamination with ovarian stromal or follicular cells that occurred during sharp-scalpel resection of the normal ovarian tissues.

Lin 28 and Lin $28 \mathrm{~B}$ primarily act as oncogenes by blocking let-7 miRNA biogenesis and subsequent depression of let-7 miRNA target genes. They were reportedly overexpressed in ovarian, colon, and oesophageal carcinoma (Peng et al, 2010; Viswanathan and Daley, 2010; King et al, 2011; Hamano et al, 2012). However, conflicting findings have emerged when assessing survival in ovarian cancer. On the basis of publicly accessible microarray data obtained from EOC tumours, Viswanathan et al (2009) reported that Lin 28 is predominantly expressed in tumours of advanced histological grade. The overexpression of Lin28B in high-grade serous ovarian cancers was shown to associate with shorter PFS and OS (Helland et al, 2011). In contrast, Lu et al (2009) found no significant correlation between Lin28 expression levels and tumour grade, disease stage or OS. Our results differ from these 
aforementioned reports as they were obtained using real-time RTPCR and showed that Lin28B but not Lin28 expression correlated with disease stage and PFS and OS, which may be due to an increase in aggressive tumour behaviour and platinum resistance. The differential effects exerted by $\operatorname{Lin} 28$ and Lin $28 \mathrm{~B}$ may be because Lin 28 has been linked to developmental and metabolic processes (Mayr and Heinemann, 2013).

Lin28/Lin28B has been suggested to have a significant role in the transformation of cancer stem-like cells, contributing to tumour aggressiveness and metastasis (Viswanathan et al, 2009; Peng et al, 2010). It has also been reported that platinum treatment is unable to remove a core population of cancer stem-like cells that are not only very invasive but are also able to cause relapse (Latifi et al,2011). Recurrent ovarian tumours are enriched with cancer stem-like cells and stem-cell pathway mediators, suggesting that cancer stem-like cells may contribute to chemoresistance and recurrent disease (Steg et al, 2012). Lu et al (2012) reported that patients with high Lin28B expression also had a higher risk of relapse and mortality than those with lower expression. Our results also demonstrated that high Lin28B expression is associated with chemoresistance and a high risk of recurrence in advanced-stage EOC patients.

The cytotoxicity of chemotherapeutic agents in cancer cells is dependent on their rates of uptake and extrusion. HCTR1 expression is frequently reduced in cisplatin-resistant cells (Kuo et al, 2007), and hCTR1 mRNA levels in tumours are associated with clinical response to platinum-based chemotherapy in ovarian cancer. However, it remains unclear how Lin28/Lin28B regulates plasma-membrane transporters and the transportation of chemotherapeutic agents into and out of cancer cells. hCTR1 is a transmembrane protein that imports copper and cisplatin into mammalian cells. Herein, the effect of Lin28/Lin28B in regulation of cisplatin resistance could be explained by its inhibitory effect on hCTR1 expression. This work is the first study to demonstrate a direct link between IMP3/Lin28B and cisplatin uptake. Our results further suggest that the effects of IMP 3 and Lin28B on hCTR1 expression and function may be through different mechanisms.

EOC is a highly heterogeneous disease that consists of four major histologic subtypes: serous, endometrioid, clear-cell, and mucinous carcinoma. Our data reveal an association of IMP3 and Lin28B with chemoresistance in various cell types, such as A2780CP70 (endometrioid), SKOV3 and OVCAR3 (serous), and BG-1, TOV-21G and ES2 cells (clear cell; Anglesio et al, 2013; Domcke et al, 2013). Our clinical data also indicate that IMP3 and Lin28B mRNA expression levels do not differ among tumour cell types and tumour grade (Table $1 \mathrm{~A})$. These findings indicate that the link between IMP3 and Lin28B transcription and chemoresistance is likely a common phenomenon in EOC.

We provide evidence of certain roles for IMP3 and Lin28B in EOC clinical outcomes. In our cohorts, the integration of data on IMP3 and Lin28B levels could help to identify those patients with worse predicted outcomes. The redirection of these patients to alternate therapies, such as dose-dense chemotherapy (Katsumata et al, 2009) or the combination of chemotherapy with targeted therapeutic agents (Penson et al, 2010; Heitz et al, 2012), could then be implemented to prolong PFS and improve long-term prognosis. Furthermore, our data suggest that strategies to enhance hCTR1 expression may overcome platinum resistance in ovarian cancer patients with elevated IMP3 and Lin28B.

\section{ACKNOWLEDGEMENTS}

We thank Ms Ching-Lin Wu and Yuan-Jhe Chuang for their assistance in collecting patient clinical information. This work was supported by grants from the National Cheng Kung University Hospital (NCKUH-9904019) and National Science Council of Taiwan (NSC 98 -2314-B-006 -039 -MY3, NSC 102-2314-B-006 049 -MY2).

\section{CONFLICT OF INTEREST}

The authors declare no conflict of interest.

\section{REFERENCES}

Anglesio MS, Wiegand KC, Melnyk N, Chow C, Salamanca C, Prentice LM, Senz J, Yang W, Spillman MA, Cochrane DR, Shumansky K, Shah SP, Kalloger SE, Huntsman DG (2013) Type-specific cell line models for type-specific ovarian cancer research. PLoS One 8: e72162.

Bashirullah A, Cooperstock RL, Lipshitz HD (1998) RNA localization in development. Annu Rev Biochem 67: 335-394.

Cheng SW, Tsai HW, Lin YJ, Cheng PN, Chang YC, Yen CJ, Huang HP, Chang TT, Lee CT, Chao A, Chou CY, Chan SH, Chow NH, Ho CL (2013) Lin28B is an oncofetal circulating cancer stem cell marker associated with recurrence of hepatocellular carcinoma. PLoS One 8: e80053.

Chen HH, Yan JJ, Chen WC, Kuo MT, Lai YH, Lai WW, Liu HS, Su WC (2012) Predictive and prognostic value of human copper transporter 1 (hCtrl) in patients with stage III non-small-cell lung cancer receiving first-line platinum-based doublet chemotherapy. Lung Cancer 75: 228-324.

Domcke S, Sinha R, Levine DA, Sander C, Schultz N (2013) Evaluating cell lines as tumour models by comparison of genomic profiles. Nat Commun 4: 2126.

Esquela-Kerscher A, Slack FJ (2006) Oncomirs -microRNAs with a role in cancer. Nat Rev Cancer 6: 259-269.

Findeis-Hosey JJ, Xu H (2011) The use of insulin like-growth factor II messenger RNA binding protein-3 in diagnostic pathology. Hum Pathol 42: 303-314.

Grieco A, Rzeczkowska P, Alm C, Palmert MR (2013) Investigation of peripubertal expression of Lin28a and Lin28b in C57BL/6 female mice. Mol Cell Endocrinol 365: 241-248.

$\mathrm{Gu}$ L, Shigemasa K, Ohama K (2004) Increased expression of IGF II mRNAbinding protein $1 \mathrm{mRNA}$ is associated with an advanced clinical stage and poor prognosis in patients with ovarian cancer. Int J Oncol 24: 671-678.

Guo Y, Chen Y, Ito H, Watanabe A, Ge X, Kodama T, Aburatani H (2006) Identification and characterization of lin-28 homolog B (LIN28B) in human hepatocellular carcinoma. Gene 384: 51-61.

Hall MD, Okabe M, Shen DW, Liang XJ, Gottesman MM (2008) The role of cellular accumulation in determining sensitivity to platinum-based chemotherapy. Annu Rev Pharmacol Toxicol 48: 495-535.

Hamano R, Miyata H, Yamasaki M, Sugimura K, Tanaka K, Kurokawa Y, Nakajima K, Takiguchi S, Fujiwara Y, Mori M, Doki Y (2012) High expression of Lin28 is associated with tumor aggressiveness and poor prognosis of patients in oesophagus cancer. Br J Cancer 106: 1415-1423.

Heitz F, Harter P, Barinoff J, Beutel B, Kannisto P, Grabowski JP, Heitz J, Kurzeder C, du Bois A (2012) Bevacizumab in the treatment of ovarian cancer. Adv Ther 29: 723-735.

Helland A, Anglesio MS, George J, Cowin PA, Johnstone CN, House CM, Sheppard KE, Etemadmoghadam D, Melnyk N, Rustgi AK, Phillips WA, Johnsen H, Birrer MJ. Australian Ovarian Cancer Study GroupPearson RB, Børresen-Dale AL, Huntsman DG, de Fazio A, Creighton CJ, Smyth GK, Bowtell DD (2011) Deregulation of MYCN, LIN28B and LET7 in a molecular subtype of aggressive high-grade serous ovarian cancers. PLoS One 6: e18064.

Hsu CC, Chiang CW, Cheng HC, Chang WT, Chou CY, Tsai HW, Lee CT, Wu ZH, Lee TY, Chao A, Chow NH, Ho CL (2011) Identifying LRRC16B as an oncofetal gene with transforming enhancing capability using a combined bioinformatics and experimental approach. Oncogene 30: 654-667.

Holzer AK, Manorek GH, Howell SB (2006) Contribution of the major copper influx transporter CTR1 to the cellular accumulation of cisplatin, carboplatin, and oxaliplatin. Mol Pharmacol 70: 1390-1394.

Ip V, Liu JJ, McKeage MJ (2013) Evaluation of effects of copper histidine on copper transporter 1-mediated accumulation of platinum and oxaliplatin- 
induced neurotoxicity in vitro and in vivo. Clin Exp Pharmacol Physiol 40: 371-378.

Ishida S, Lee J, Thiele DJ, Herskowitz I (2002) Uptake of the anticancer drug cisplatin mediated by the copper transporter Ctr1 in yeast and mammals. Proc Natl Acad Sci USA 99: 14298-14302.

Ishida S, McCormick F, Smith-McCune K, Hanahan D (2010) Enhancing tumor-specific uptake of the anticancer drug cisplatin with a copper chelator. Cancer Cell 17: 574-583.

Jeng YM, Chang CC, Hu FC, Chou HY, Kao HL, Wang TH, Hsu HC (2008) RNA-binding protein insulin like growth factor II mRNA-binding protein 3 expression promotes tumor invasion and predicts early recurrence and poor prognosis in hepatocellular carcinoma. Hepatology 48: 1118-1127.

Jiang Z, Chu PG, Woda BA, Rock KL, Liu Q, Hsieh CC, Li C, Chen W, Duan HO, McDougal S, Wu CL (2006) Analysis of RNA-binding protein IMP3 to predict metastasis and prognosis of renal-cell carcinoma: a retrospective study. Lancet Oncol 7: 556-564.

Katsumata N, Yasuda M, Takahashi F, Isonishi S, Jobo T, Aoki D, Tsuda H, Sugiyama T, Kodama S, Kimura E, Ochiai K, Noda K. Japanese Gynecologic Oncology Group (2009) Dose-dense paclitaxel once a week in combination with carboplatin every 3 weeks for advanced ovarian cancer: a phase 3, open-label, randomised controlled trial. Lancet 374: 1331-1338.

King CE, Cuatrecasas M, Castells A, Sepulveda AR, Lee JS, Rustgi AK (2011) LIN28B promotes colon cancer progression and metastasis. Cancer Res 71: 4260-4268.

Köbel M, Xu H, Bourne PA, Spaulding BO, Shih IeM, Mao TL, Soslow RA, Ewanowich CA, Kalloger SE, Mehl E, Lee CH, Huntsman D, Gilks CB (2009) IGF2BP3 (IMP3) expression is a marker of unfavorable prognosis in ovarian carcinoma of clear cell subtype. Mod Pathol 22: 469-475.

Kumar MS, Lu J, Mercer KL, Golub TR, Jacks T (2007) Impaired microRNA processing enhances cellular transformation and tumorigenesis. Nat Genet 39: 673-677.

Kuo MT, Chen HH, Song IS, Savaraj N, Ishikawa T (2007) The roles of copper transporters in cisplatin resistance. Cancer Metastasis Rev 26: 71-83.

Latifi A, Abubaker K, Castrechini N, Ward AC, Liongue C, Dobill F, Kumar J, Thompson EW, Quinn MA, Findlay JK, Ahmed N (2011) Cisplatin treatment of primary and metastatic epithelial ovarian carcinomas generates residual cells with mesenchymal stem cell-like profile. J Cell Biochem 112: 2850-2864.

Liao B, Hu Y, Herrick DJ, Brewer G (2005) The RNAbinding protein IMP-3 is a translational activator of insulin-like growth factor II leader-3 mRNA during proliferation of human K562 leukemia cells. J Biol Chem 280: 18517-18524.

Lochhead P, Imamura Y, Morikawa T, Kuchiba A, Yamauchi M, Liao X, Qian ZR, Nishihara R, Wu K, Meyerhardt JA, Fuchs CS, Ogino S (2012) Insulin-like growth factor 2 messenger RNA binding protein 3 (IGF2BP3) is a marker of unfavourable prognosis in colorectal cancer. Eur J Cancer 48: 3405-3413.

Lu L, Katsaros D, Mayne ST, Risch HA, Benedetto C, Canuto EM, Zhang K, Conner M, Landen CN (2012) Functional study of risk loci of stem cellassociated gene lin-28B and associations with disease survival outcomes in epithelial ovarian cancer. Carcinogenesis 33: 2119-2125.

Lu L, Katsaros D, Shaverdashvili K, Qian B, Wu Y, de la Longrais IA, Preti M, Menato G, Yu H (2009) Pluripotent factor lin-28 and its homologue lin$28 \mathrm{~b}$ in epithelial ovarian cancer and their associations with disease outcomes and expression of let-7a and IGF-II. Eur J Cancer 45: 2212-2218.

Mayr F, Heinemann U (2013) Mechanisms of Lin28-mediated miRNA and mRNA regulation-a structural and functional perspective. Int J Mol Sci 14: 16532-16553.

Nielsen FC, Nielsen J, Christiansen J (2001) A family of IGF-II mRNA binding proteins (IMP) involved in RNA trafficking. Scand J Clin Lab Invest Suppl 234: 93-99.

Nielsen FC, Nielsen J, Kristensen MA, Koch G, Christiansen J (2002) Cytoplasmic trafficking of IGF-II mRNA-binding protein by conserved KH domains. J Cell Sci 115: 2087-2097.
Nielsen J, Christiansen J, Lykke-Andersen J, Johnsen AH, Wewer UM, Nielsen FC (1999) A family of insulin-like growth factor II mRNA-binding proteins represses translation in late development. Mol Cell Biol 19: 1262-1270.

Peng S, Maihle NJ, Huang Y (2010) Pluripotency factors Lin28 and Oct4 identify a subpopulation of stem cell-like cells in ovarian cancer. Oncogene 29: 2153-2159.

Penson RT, Dizon DS, Cannistra SA, Roche MR, Krasner CN, Berlin ST, Horowitz NS, Disilvestro PA, Matulonis UA, Lee H, King MA, Campos SM (2010) Phase II study of carboplatin, paclitaxel, and bevacizumab with maintenance bevacizumab as first-line chemotherapy for advanced mullerian tumors. J Clin Oncol 28: 154-159.

Polesskaya A, Cuvellier S, Naguibneva I, Duquet A, Moss EG, Harel-Bellan A (2007) Lin-28 binds IGF-2 mRNA and participates in skeletal myogenesis by increasing translation efficiency. Genes Dev 21: 1125-1138.

Reinhart BJ, Slack FJ, Basson M, Pasquinelli AE, Bettinger JC, Rougvie AE, Horvitz HR, Ruvkun G (2000) The 21-nucleotide let-7 RNA regulates developmental timing in Caenorhabditis elegans. Nature 403: 901-906.

Sarkar B, Lingertat-Walsh K, Clarke JTR (1993) Copper-histidine therapy for Menkes disease. J Pediatr 123: 828-830.

Steg AD, Bevis KS, Katre AA, Ziebarth A, Dobbin ZC, Alvarez RD, Zhang K, Conner M, Landen CN (2012) Stem cell pathways contribute to clinical chemoresistance in ovarian cancer. Clin Cancer Res 18: 869-881.

Vikesaa J, Hansen TV, Jonson L, Borup R, Wewer UM, Christiansen J, Nielsen FC (2006) RNA-binding IMPs promote cell adhesion and invadopodia formation. $E M B O J$ 25: 1456-1468.

Viswanathan SR, Powers JT, Einhorn W, Hoshida Y, Ng TL, Toffanin S, O'Sullivan M, Lu J, Phillips LA, Lockhart VL, Shah SP, Tanwar PS, Mermel CH, Beroukhim R, Azam M, Teixeira J, Meyerson M, Hughes TP, Llovet JM, Radich J, Mullighan CG, Golub TR, Sorensen PH, Daley GQ (2009) Lin28 promotes transformation and is associated with advanced human malignancies. Nat Genet 41: 843-848.

Viswanathan SR, Daley GQ (2010) Lin28: A microRNA regulator with a macro role. Cell 140: 445-449.

Xue D, Peng Y, Wang F, Allan RW, Cao D (2011) RNA-binding protein LIN28 is a sensitive marker of ovarian primitive germ cell tumours. Histopathology 59: 452-459.

Yaniv K, Yisraeli JK (2002) The involvement of a conserved family of RNA binding proteins in embryonic development and carcinogenesis. Gene 287: 49-54.

Yantiss RK, Woda BA, Fanger GR, Kalos M, Whalen GF, Tada H, Andersen DK, Rock KL, Dresser K (2005) KOC (K homology domain containing protein overexpressed in cancer): a novel molecular marker that distinguishes between benign and malignant lesions of the pancreas. Am J Surg Pathol 29: 188-195.

Yuan RH, Wang CC, Chou CC, Chang KJ, Lee PH, Jeng YM (2009) Diffuse expression of RNA-binding protein IMP3 predicts high-stage lymph node metastasis and poor prognosis in colorectal adenocarcinoma. Ann Surg Oncol 16: 1711-1719.

Yu J, Vodyanik MA, Smuga-Otto K, Antosiewicz-Bourget J, Frane JL, Tian S, Nie J, Jonsdottir GA, Ruotti V, Stewart R, Slukvin, Thomson JA (2007) Induced pluripotent stem cell lines derived from human somatic cells. Science 318: 1917-1920.

Zheng W, Yi X, Fadare O, Liang SX, Martel M, Schwartz PE, Jiang Z (2008) The oncofetal protein IMP3: a novel biomarker for endometrial serous carcinoma. Am J Surg Pathol 32: 304-315.

This work is published under the standard license to publish agreement. After 12 months the work will become freely available and the license terms will switch to a Creative Commons AttributionNonCommercial-Share Alike 4.0 Unported License.

Supplementary Information accompanies this paper on British Journal of Cancer website (http://www.nature.com/bjc) 